
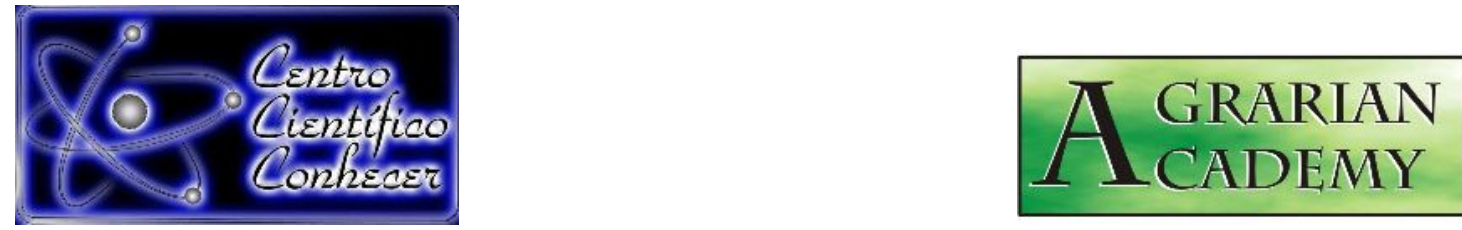

\title{
PERDAS NA COLHEITA MECANIZADA DE GRÃOS DE SOJA NO SUDOESTE DO PARANÁ
}

\footnotetext{
Antônio Carlos Marangoni De Cól ${ }^{1}$, Lucas Dotto ${ }^{2 *}$, Alcir José Modolo², Maicon Sgarbossa ${ }^{2}$.

${ }^{1}$ Engenheiro Agrônomo, Universidade Tecnológica Federal do Paraná (UTFPR) Pato Branco, PR, Brasil.

${ }^{2}$ Programa de Pós-graduação em Agronomia, Universidade Tecnológica Federal do Paraná (UTFPR) - Pato Branco, PR, Brasil. *(lucas.dotto3@gmail.com)

Recebido em: 02/06/2019 - Aprovado em: 15/06/2019 - Publicado em: 22/07/2019 DOI: 10.18677/Agrarian_Academy_2019a23
}

\begin{abstract}
RESUMO
Atualmente vários trabalhos vêm sendo realizados visando a quantificação de perdas de soja pelo Brasil, já para a região Sudoeste do Paraná são poucos os relatos descritos. Dessa forma, o presente estudo tem como objetivo quantificar as perdas de grãos de soja, durante a colheita mecanizada na região Sudoeste do Paraná. O trabalho foi realizado em dezessete propriedades produtoras de soja, avaliando-se as perdas das colhedoras. Foram realizadas entrevistas com os operadores dos maquinários para aquisição de dados quanto ao tempo de exercício da profissão e realizações de treinamentos para uso das máquinas. A determinação quantitativa das perdas na colheita da cultura, foram divididas em perdas de précolheita e perdas de pós-colheita. A quantificação da produtividade e das perdas na pré-colheita foram mensuradas de forma manual, em que era utilizado uma armação retangular, com área útil de 2,0 $\mathrm{m}^{2}$. Dos dezessete operadores avaliados, 47,06\% possuem menos de dez anos de profissão nessa atividade. Na região Sudoeste do Paraná, $94,12 \%$ das colhedoras perdem mais do que os níveis aceitáveis durante a colheita da soja, com média de $206,75 \mathrm{~kg} \mathrm{ha}^{-1}$. A região sudoeste do Paraná apresenta perdas superiores ao aceitável, o que podem estar relacionadas ao tempo de profissão, falta de capacitação dos operadores, ao uso de plataformas maiores que 25 pés em terrenos irregulares e também pela maioria das cultivares analisadas possuírem em média baixa inserção de vagem, o que dificulta o corte da planta.

PALAVRAS-CHAVE: Agricultura. Mecanização. Produtividade.
\end{abstract}

\section{LOSSES ON MECHANIZED SOYBEAN HARVEST IN SOUTHWEST OF PARANÁ}

\section{ABSTRACT}

Currently, several studies have been carried out aiming at the quantification of soybean losses in Brazil, and for the Southwest region of Paraná, few reports have been described. Thus, the present work aims to quantify the losses of soybean 
grains during the mechanized harvest in the Southwest region of Paraná. The work was carried out in seventeen soy producing properties, evaluating the losses of the harvesters. Interviews were carried out with the machinery operators to acquire data regarding the time of exercise of the profession and the accomplishment of trainings for the use of the machines. The quantitative determination of crop losses were divided into pre-harvest losses and postharvest losses. The quantification of productivity and losses in the pre-harvest were measured manually, using a rectangular frame, with floor area of $2.0 \mathrm{~m}^{2}$. The data were submitted to an exploratory analysis through a descriptive statistic and the results are presented in graph form. Of the seventeen operators evaluated, $47.06 \%$ have less than ten years of profession in this activity. In the Southwest region of Paraná, 94.12\% of the harvesters lose more than acceptable levels during the soybean harvest, with a mean of $206.75 \mathrm{~kg}$ ha-1. The southwestern region of Paraná has higher than acceptable losses, which may be related to the time of profession, lack of capacity of the operators, the use of platforms larger than 25 feet in irregular terrain and also by the majority of the cultivars analyzed have, on average, low insertion of pod, which makes it difficult to cut the plant.

KEY-WORDS: Agriculture. Mechanization. Productivity.

\section{INTRODUÇÃO}

A cultura da soja possui grande importância econômica e social, devido a sua possibilidade de produção em qualquer região do país e também à sua participação na cadeia alimentar humana e animal. De acordo com a USDA (2018) os Estados Unidos é o país que possui a maior produção dessa cultura em segundo lugar vem o Brasil com uma produção de 119,3 milhões de toneladas (CONAB, 2018). Deste total, 19,5 milhões de toneladas são produzidas no Paraná, segundo maior produtor de soja brasileiro na safra 2016/2017, totalizando 5,3 milhões de hectares de área plantada e produtividade de $3.721 \mathrm{~kg} \mathrm{ha}^{-1}$ (EMBRAPA, 2018). Dados oficiais de 2015 apontam que 4 municípios dos 20 maiores produtores de grãos estão localizados no Paraná, estado brasileiro com destaque na agricultura (NAVARRO; BUAINAIN, 2018).

Visto a importância econômica da soja é necessário ter alguns cuidados e realizar monitoramento nas etapas de colheita, transporte e armazenamento, afim de reduzir perdas de grãos. Segundo Silveira e Conte (2013) a colheita da cultura da soja deve ser efetuada no estádio R9, quando os grãos apresentarem umidade entre 13 e 15\%, minimizando assim os danos mecânicos que ocasionam perdas.

Durante o processo de colheita é inevitável que ocorram perdas do produto, porém deve-se minimizá-las para que o lucro seja maior. De acordo com CAPECO (2015), anualmente a perda de grãos de soja está próxima a $23 \%$ da safra total, valor relativamente alto, porém dentro dos níveis de tolerância de perda na colheita mecanizada que é de $60 \mathrm{~kg} \mathrm{ha}^{-1}$ (SILVEIRA; CONTE, 2013).

As perdas na colheita mecanizada podem ser afetadas por vários fatores, entre eles o mal preparo do solo, formando desníveis no terreno fazendo com que a plataforma de corte trabalhe em altura desuniforme, inadequação da época de semeadura, do espaçamento e densidade, utilização de cultivares não adaptadas a região, presença de plantas daninhas e umidade inadequada. Porém, a maior quantidade de perdas ocorre devido à má regulagem e forma de operação da colhedora (BOTTEGA et al., 2014). Atualmente vários trabalhos vêm sendo realizados visando a quantificação de perdas de soja pelo Brasil, já para a região Sudoeste do Paraná são poucos os relatos descritos. 
Dessa forma, o presente trabalho tem como objetivo quantificar as perdas de grãos de soja, durante a colheita mecanizada na região Sudoeste do Paraná.

\section{METODOLOGIA}

O trabalho foi realizado em dezessete propriedades produtoras de soja, avaliando-se as perdas na colheita na região Sudoeste do Paraná, durante os meses de janeiro e fevereiro de 2016. A região encontra-se a $765 \mathrm{~m}$ de altitude, com

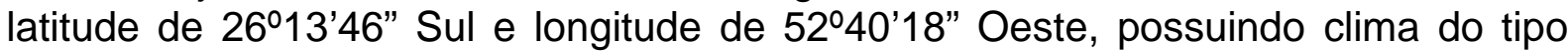
Cfa, subtropical úmido conforme classificação de (ALVARES et al. 2013). As características das máquinas e tamanho das propriedades produtoras de grãos, são apresentados na tabela 1 .

Tabela 1. Tamanho de área e características das máquinas avaliadas.

\begin{tabular}{cccc}
\hline Tamanho da área (ha) & Modelo & Ano de Fabricação & Fabricante \\
\hline 33,88 & TC 57 & 2008 & New Holland \\
13,31 & TC 57 & 2008 & New Holland \\
33,88 & TC 55 & 2004 & New Holland \\
21,78 & 5070 & 2014 & New Holland \\
72,6 & 5070 & 2014 & New Holland \\
9,68 & TC 57 & 2007 & New Holland \\
53,24 & TC 57 & 1998 & New Holland \\
13,31 & CR 6080 & 2014 & New Holland \\
16,94 & TC 57 & 2005 & New Holland \\
13,31 & STS 9770 & 2011 & John Deere \\
31,46 & STS 9770 & 2011 & John Deere \\
33,88 & STS 9670 & 2013 & John Deere \\
48,4 & STS 9670 & 2013 & John Deere \\
14,52 & 1450 & 2002 & John Deere \\
24,2 & STS 9470 & 2011 & John Deere \\
15,73 & 2566 & 2012 & Case \\
50,82 & 2566 & 2012 & Case \\
\hline
\end{tabular}

Para a aquisição dos dados em relação aos operadores, foram realizadas entrevistas, sendo questionado, o tempo de exercício da profissão e se possuíam algum tipo de treinamento para manutenção ou uso do maquinário. Também foi realizado levantamento se o maquinário utilizado nas propriedades era próprio ou de serviço terceirizado.

Para a determinação quantitativa das perdas na colheita da cultura da soja, as mesmas foram divididas em perdas de pré-colheita (perdas naturais), perdas de póscolheita (perda na plataforma de corte e no sistema de trilha) (ACOSTA et al., 2018). Em cada ponto da amostragem foi delimitada uma área de 2,0 $\mathrm{m}^{2}$, dentro de uma armação retangular, construída com duas barras de PVC e dois cordões de nylon, sendo realizadas três coletas para cada avaliação.

A quantificação da produtividade foi mensurada antes da colheita mecanizada de forma manual, sendo colhido as plantas existentes na área útil de $1,0 \mathrm{~m}^{2} \mathrm{e}$ posteriormente extrapolado para $\mathrm{kg} \mathrm{ha}^{-1}$.

Para a determinação da umidade dos grãos, as amostras foram coletadas no momento da colheita e acondicionadas em sacos plásticos hermeticamente fechados. Posteriormente as mesmas foram pesadas e levadas para a estufa a $105^{\circ} \mathrm{C}$ por 24 horas. Após este período foram novamente pesados. O resultado da 
umidade foi definido pela divisão entre a massa de água (g) e a massa total da amostra (g), multiplicado por 100 para obtenção do valor em porcentagem de umidade (HOLTZ et al., 2019).

Para avaliar as perdas naturais, a armação de $2,0 \mathrm{~m}^{2}$ era estendida de forma aleatória antes da entrada da colhedora na área, onde eram coletados os grãos. Já para quantificar as perdas na plataforma de corte, foi necessário parar a colhedora e recuar a mesma aproximadamente quatro metros para assim estender a armação na área de recuo, onde havia passado somente a plataforma de corte, sendo coletados os grãos que se encontravam na superfície do solo.

Os dados foram submetidos a uma análise exploratória, através de uma estatística descritiva e os resultados são apresentados em forma de gráficos.

\section{RESULTADOS E DISCUSSÃO}

Dos dezessete operadores avaliados, $47,06 \%$ possuem menos de dez anos de profissão nessa atividade (Figura 1A). Verificou-se também que $64,71 \%$ dos operadores possuem cursos de capacitação para a atividade (Figura 1B). Esse percentual é relativamente baixo, sabendo que o treinamento para os cuidados operacionais ou de regulagem dos principais componentes e mecanismos é essencial, pois influencia diretamente no controle de perdas na colheita. Meyer et al. (2015) avaliando operadores e técnicos de manutenção de máquinas agrícolas no setor canavieiro relatam que apenas $18 \%$ dos operadores entrevistados, não realizaram algum tipo de capacitação para operação de máquinas agrícolas, fazendo assim com que o desempenho operacional do maquinário seja reduzido, resultando no aumento de perdas de grãos na colheita.

A

B

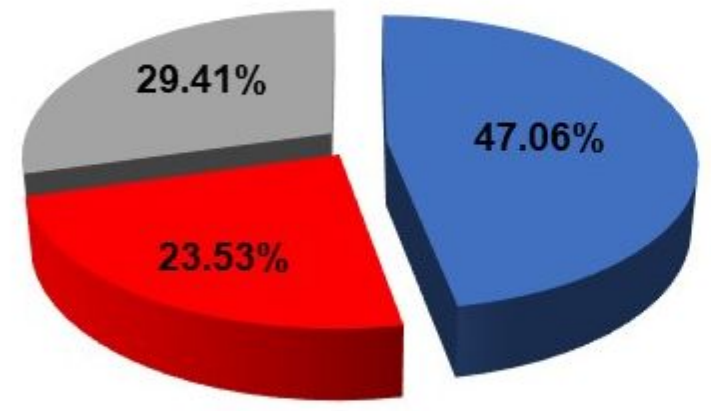

Tempo de profissão(anos)

$=0-10=10-20=20$

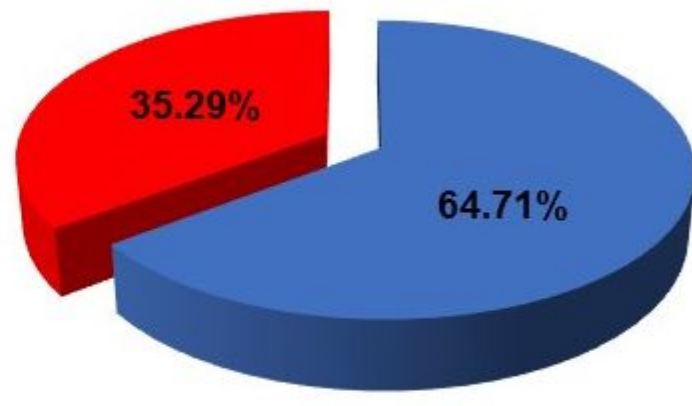

Realização de treinamentos - Sim $=$ Não

Figura 1. Tempo de profissão $(A)$ e realização de treinamento $(B)$, dos operadores entrevistados na colheita mecanizada de soja no Sudoeste do Paraná. Fonte: Autores, 2019.

A capacitação dos operadores de maquinários é de fundamental importância, visto que mesmo a propriedade tendo uma colhedora antiga, há possibilidades de diminuição nas perdas, além disso os operadores aprendem a manusear equipamentos com maior segurança e realizar aplicações de produtos com maior eficiência (CASALI et al., 2015).

Das dezessetes propriedades onde se realizou o estudo, verificou-se que apenas $35,3 \%$ delas possuíam colhedora própria (Figura 2A). Algumas vezes a 
contratação de serviços terceirizados para a realização da colheita, acaba sendo um problema ao produtor rural, isso devido a disponibilidade da máquina no momento ideal de colheita e também por excesso de velocidade adotado pelo operador terceirizado. Araújo et al. (2016) descrevem que os fornecedores de serviços de colheita terceirizados têm incentivos para aumentar a velocidade de operação, deteriorando a qualidade dos serviços prestados. Além disso, qualquer atraso na operação de uma lavoura pode deixar outra sem o serviço. Os autores ainda relatam que a operação terceirizada conta com um nível muito menor de controle do agricultor quando comparada à operação de uma colhedora própria.

A

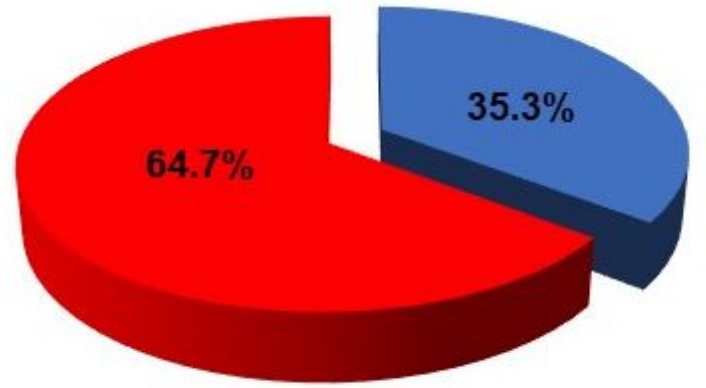

Modo de colheita de grãos

- Máquina própria - Serviço terceirizado

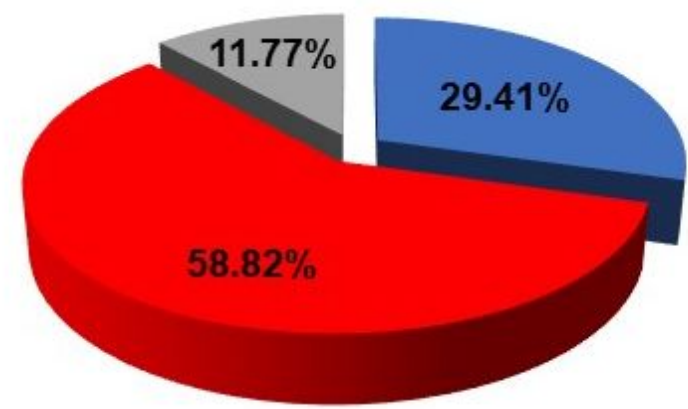

Umidade de grãos na colheita $\square<13 \quad \square 13-15 \quad \square>15(\%)$

Figura 2. Propriedades que possuem colhedora própria $(A)$ e umidade obtida no momento da colheita dos grãos de soja (B), na região Sudoeste do Paraná. Fonte: Autores, 2019.

Verificou-se que somente $58,82 \%$ dos agricultores realizaram a colheita dos grãos em umidade recomendada, entre 13 e 15\% (Figura 2B). Esse resultado se torna baixo, visto o risco o qual produtor sofre de realizar a colheita em momentos inadequados. França Neto et al. (2007) relatam que grãos de soja com umidade superior a $14 \%$ podem estar sujeitos à maior incidência de danos mecânicos latentes durante o processo de colheita, enquanto teores de umidade inferiores a $12 \%$ podem resultar em maior sensibilidade à quebra dos grãos e em prejuízos à qualidade fisiológica das sementes podendo acelerar o processo de deterioração da soja (XAVIER et al., 2015).

Observa-se para a porcentagem de perdas (Figura 3), que a plataforma de corte foi responsável pela maior parte de perda na colheita da soja $(72,58 \%)$, já as perdas naturais foram responsáveis pelo menor valor $(3,86 \%)$. Os resultados corroboram com os encontrados por Schanoski et al. (2011) estudando as perdas na colheitas mecanizada de soja no município de Maripá - PR, os quais relatam que cerca de $75 \%$ das perdas durante a colheita da soja, foram provocados pela plataforma de corte e os $25 \%$ restantes ocorreram no sistema de trilha, separação e limpeza. 


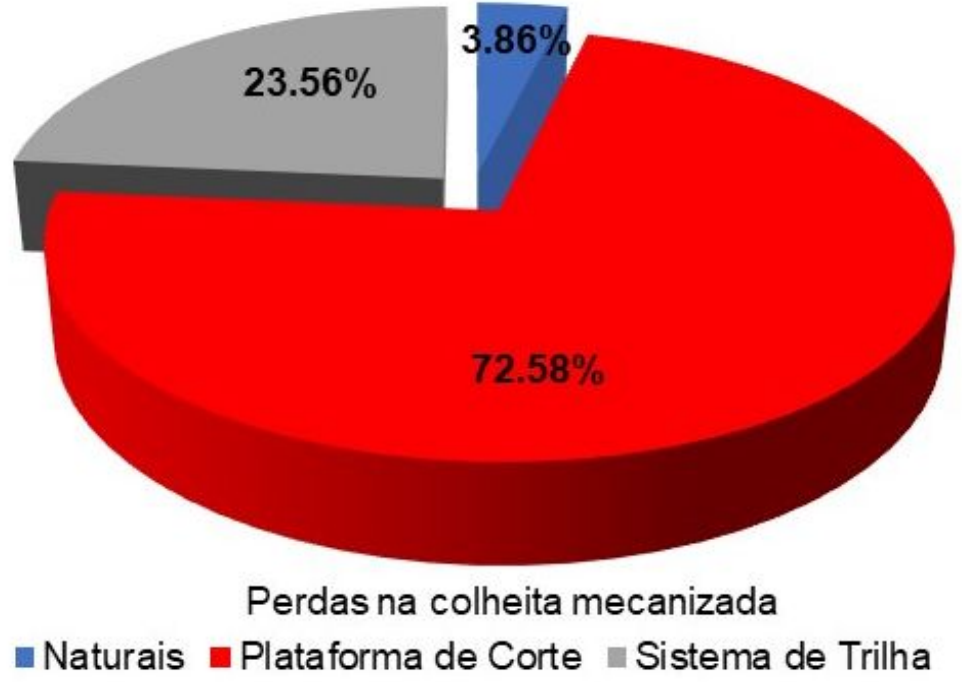

Figura 3. Porcentagem de perdas naturais, na plataforma de corte e no sistema de trilha, na colheita mecanizada da soja na safra 2015/2016 na região Sudoeste do Paraná. Fonte: Autores, 2019.

Apenas 5,88\% das colhedoras avaliadas (Figura 4) apresentaram porcentagem de perdas dentro dos limites aceitáveis, ou seja, até $60 \mathrm{~kg} \mathrm{ha}^{-1}$ (SILVEIRA; CONTE, 2013). As demais $(94,12 \%)$ variaram com perdas que chegaram até $402,09 \mathrm{~kg} \mathrm{ha}^{-1}$. As perdas médias das colhedoras foram de $206,75 \mathrm{~kg} \mathrm{ha}^{-1}$. Resultados contraditórios com o que foram encontrados por EMATER (2015) onde somente $14 \%$ das colhedoras apresentaram perdas acima dos níveis aceitáveis e a média das perdas foram de $16,8 \mathrm{~kg} \mathrm{ha}^{-1}$.

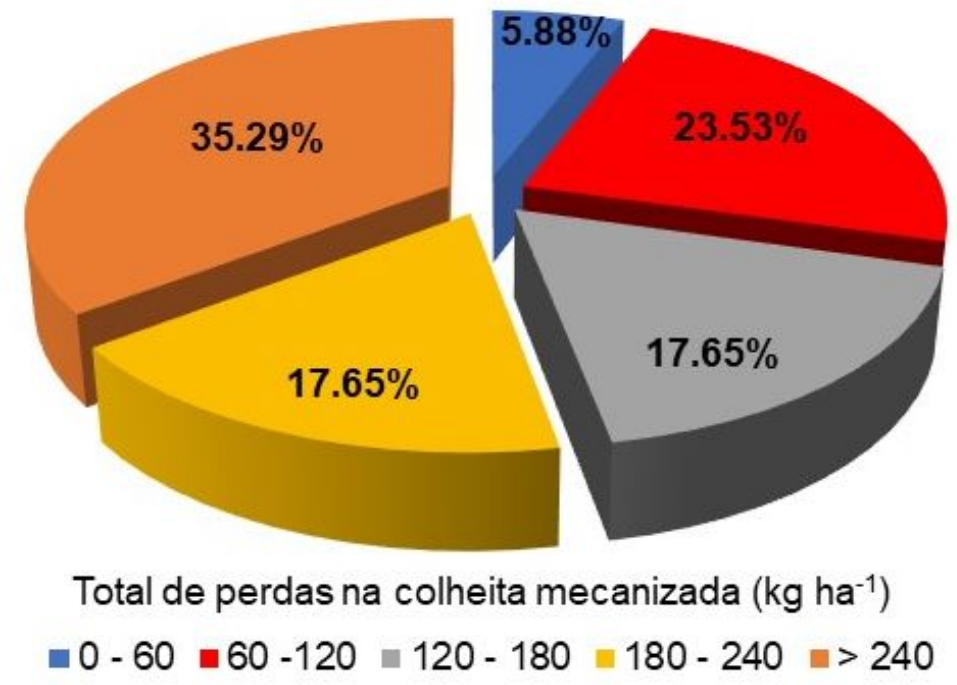

Figura 4. Perdas totais $\left(\mathrm{kg} \mathrm{ha}^{-1}\right)$ na colheita mecanizada de soja, na Região Sudoeste do Paraná. Fonte: Autores, 2019. 


\section{CONCLUSÕES}

A região sudoeste do Paraná apresenta perdas superiores ao aceitável, o que podem estar relacionadas ao tempo de profissão, falta de capacitação dos operadores, ao uso de plataformas maiores que 25 pés em terrenos irregulares e também pela maioria das cultivares analisadas possuírem em média baixa inserção de vagem, o que dificulta o corte da planta.

As maiores perdas $(72,58 \%)$ foram ocasionadas pela plataforma de corte, seguido pelo sistema de trilha $(23,56 \%)$.

\section{AGRADECIMENTOS}

Os autores agradecem ao apoio financeiro recebido da Coordenação de Aperfeiçoamento de Pessoal de Nível Superior (CAPES) e Conselho Nacional de Desenvolvimento Científico e Tecnológico (CNPq).

\section{REFERÊNCIAS}

ACOSTA, J. J. B.; CABRERA, M. G.; IBRAS, R. F.; GONZÁLEZ, J. D.; CHAMORRO, S. M.; ESCOBAR, J. Variabilidade espacial da produtividade, perdas na colheita e lucratividade da cultura da soja. Revista Agrogeoambiental, v. 10, n. 1, p. 27-46, 2018. Disponível em: <http://dx.doi.org/10.18406/2316-1817v10n120181050>. doi: 10.18406/2316-1817v10n120181050.

ALVARES, C. A.; STAPE, J. L.; SENTELHAS, P. C.; GONÇALVES, J. L. M.; SPAROVEK, G. Köppen's climate classification map for Brazil. Meteorologische Zeitschrift, v. 22, n. 6, p. 711-728, 2013. Disponível em: <https://doi.org/10.1127/0941-2948/2013/0507>. doi.org/10.1127/0941$2948 / 2013 / 0507$

ARAÚJO, J. M. M.; GOMES, M. C.; CARRARO, A. Os incentivos econômicos à compra de colhedoras pelo Pronaf-Mais alimentos para os produtores de arroz irrigado do Rio Grande do Sul. Revista Brasileira de Políticas Públicas, v. 6, n. 1, p. 69-82, 2016. Disponível em: <https://www.publicacoesacademicas.uniceub.br/RBPP/article/view/3540> doi: 10.5102/rbpp.v6i1.3540

BOTTEGA, E. L.; SOUZA, C. M. A.; RAFULL, L. Z. L.; QUEIROZ, D. M. Avaliação de uma colhedora e da qualidade de sementes de forragem colhidas por varredura.

Campo Digit@I, v. 9, n. 1, p. 10-20, 2014. Disponível em: $<$ http://revista2.grupointegrado.br/revista/index.php/campodigital/article/view/1662/58 $4>$.

CAPECO - Cámara Paraguaya de Exportadores y Comercializadores de Cereales y oleaginosas. Ranking Mundial. 2015. Disponível em: <http://capeco.org.py/rankingmundial-es>.

CASALI, A. L.; SCHLOSSER, J. F.; GANDOLFO, M. A.; UHRY, D.; RODRIGUES, F. A. Nível de capacitação e informação dos operadores de máquinas para a aplicação de agrotóxicos. Ciểncia Rural, v. 45, n. 3, p. 425-431, 2015. Disponível em: <http://dx.doi.org/10.1590/0103-8478cr20121099>. doi: 10.1590/01038478 cr20121099 
CONAB - COMPANHIA NACIONAL DE ABASTECIMENTO- Acompanhamento safra brasileira de grãos. v.6 Safra 2018/19 - Terceiro levantamento, Brasília, p.1127, dezembro 2018.2 Disponível em: <https://www.conab.gov.br/component/k2/item/download/23679_041c465fb71e41cf3 82825c6b8c43623>.

EMATER - INSTITUTO PARANAENSE DE ASSISTÊNCIA TÉCNICA E EXTENSÃO RURAL. Perdas na colheita mecanizada da SOJA - Safra 2014/2015. Curitiba PR, 2015.2 Disponível em: <http://www.emater.pr.gov.br/arquivos/File/Biblioteca_Virtual/Relatos_Resultados_e_ Planejamentos/Perdas_na_Colheita/Rel_perdas_colheita_safra_2014_2015.pdf>.

EMBRAPA - Empresa Brasileira de Pesquisa Agropecuária. Embrapa soja: Soja em números (safra 2016/2017). 2018. Disponível em: <https://www.embrapa.br/en/soja/cultivos/soja1/dados-economicos>.

FRANÇA NETO, J. B.; KRZYZANOWSKI, F. C.; HENNING, A. A.; PÁDUA, G. P.; LORINI, I.; HENNING, F. A. Tecnologia da produção de sementes de soja de alta qualidade. Londrina: Embrapa Soja, 2016. 82p. Disponível em: $<$ https://ainfo.cnptia.embrapa.br/digital/bitstream/item/151223/1/Documentos-380OL1.pdf>.

HOLTZ, V.; GRELLMANN, D. H.; AZEVEDO, R. O.; KOESTER, B. E. G.; JARDIM, C. C. S.; MASSOLA, M. P.; REIS, R. G. E. Perdas na colheita mecanizada de soja utilizando diferentes mecanismos na plataforma de corte. PUBVET, v. 13, n. 2, p. 16, 2019. Disponível em: <https://doi.org/10.31533/pubvet.v13n2a261.1-6>. doi: 10.31533/pubvet.v13n2a261.1-6

MEYER, W.; COMPAGNON, A. M.; LOPES, R. A. P.; ARRIEL, F. H.; GUILHERME, I. H. Avaliação de operadores e técnicos de manutenção de máquinas agrícolas no setor canavieiro. Multi-Science Journal, v. 1, n. 3, p. 64-68, 2015. Disponível em: <https://www.ifgoiano.edu.br/periodicos/index.php/multiscience/article/view/68>.

NAVARRO, Z.; BUAINAIN, A. M. The global driving of Brazilian agrarian development in the new century. In: Globalization and agriculture: Redefining unequal development. Estados Unidos da América: Lexington Books, 2018. p. 9-3. Disponível em: <https://rowman.com/ISBN/9781498542265/Globalization-andAgriculture-Redefining-Unequal-Development>.

SCHANOSKI, R.; RIGHI, E. Z.; WERNER, V. Perdas na colheita mecanizada de soja (Glycine max) no município de Maripá - PR. Revista Brasileira de Engenharia Agrícola e Ambiental, v.15, n.11, p.1206-1211, 2011. Disponível em: <http://dx.doi.org/10.1590/S1415-43662011001100015>. doi: 10.1590/S141543662011001100015

SILVEIRA, J. M.; CONTE, O. Determinação de perdas na colheita de soja: copo medidor da Embrapa. Londrina - PR. p.28, 2013. Disponível em: $<$ https://ainfo.cnptia.embrapa.br/digital/bitstream/item/97495/1/Manual-CopoMedidor-baixa-completo.pdf>. 
USDA - United States Departamento of Agriculture. Table 11 Soybean Area, Yeld, and Production. 2018.2 Dísponivel em: <https://apps.fas.usda.gov/psdonline/reportHandler.ashx?fileName=Table\%2011\%20 Soybean\%20Area,\%20Yield,\%20and\%20Production\&reportld=906\&templateld=1\&fo rmat=html>.

XAVIER, T. S.; DARONCH, D. J.; PELUZIO, J. M.; AFFERI, F. S.; CARVALHO, E. V.; SANTOS, W. F. Época de colheita na qualidade de sementes de genótipo de soja. Comunicata Scientiae, v. 6, n. 2, p. 241-245, 2015. Disponível em $<$ https://dialnet.unirioja.es/descarga/articulo/6294657.pdf>. 